EVIDENCE BASED PUBLIC HEALTH POLICY AND PRACTICE

\title{
Population impact of stricter adherence to recommendations for pharmacological and lifestyle interventions over one year in patients with coronary heart disease
}

\author{
I Gemmell, R F Heller, P McElduff, K Payne, G Butler, R Edwards, M Roland, P Durrington
}

J Epidemiol Community Health 2005;59:1041-1046. doi: 10.1136/jech.2005.035717

See end of article for authors' affiliations

Correspondence to: Dr I Gemmell, Evidence for Public Health Unit, School of Epidemiology and Health Sciences, University of Manchester, Oxford Road, Manchester M13 9PT, UK; islay.gemmell@ man.ac.uk

Accepted for publication 27 July 2005
Study objective: To assess the potential number of lives saved associated with the full implementation of aspects of the National Service Framework (NSF) for coronary heart disease (CHD) in England using recently developed population impact measures.

Design: Modelling study.

Setting: Primary care.

Data sources: Published data on prevalence of acute myocardial infarction and heart failure, baseline risk of mortality, the relative risk reduction associated with different interventions and the proportion treated, eligible for treatment and adhering to each intervention.

Main results: Adopting the NSF recommendations for pharmacological interventions would prevent an extra 1027 (95\% Cl 418 to 1994) deaths in post-acute myocardial infarction (AMI) patients and an extra 37899 (95\% Cl 25690 to 52503 ) deaths in heart failure patients in the first year after diagnosis. Lifestyle based interventions would prevent an extra $848(95 \% \mathrm{Cl} 71$ to 1614$)$ deaths in post-AMl patients and an extra $7249(95 \% \mathrm{Cl} 995$ to 16 696) deaths in heart failure patients.

Conclusions: Moving from current to "best" practice as recommended in the NSF will have a much greater impact on one year mortality rates among heart failure patients compared with post-AMI patients. Meeting pharmacological based recommendations for heart failure patients will prevent more deaths than meeting lifestyle based recommendations. Population impact numbers can help communicate the impact on a population of the implementation of guidelines and, when created using local data, could help policy makers assess the local impact of implementing a range of health care targets.
$\mathrm{P}$ opulation impact measures provide a population focus to the interpretation of the results of observational studies and randomised controlled trials ${ }^{12}$ and hence provide a population perspective to evidence based practice. ${ }^{3}$ These measures can be used to estimate the impact on the population of implementing health care recommendations. In March 2000 the UK government introduced the National Service Framework (NSF) for coronary heart disease (CHD) ${ }^{4}$ This NSF recommends, among other things, provision of appropriate treatment to post-acute myocardial infarction (AMI) patients (standards seven and twelve) and to patients with heart failure (standard eleven). Specifically the NSF recommends that $80 \%-90 \%$ of post-AMI patients are prescribed aspirin, $\beta$ blockers, statins, and ACE inhibitors where appropriate and that $80 \%-90 \%$ of heart failure patients are prescribed diuretics, $\beta$ blockers, and ACE inhibitors. The NSF also recommends that post-AMI and heart failure patients should be given advice on smoking cessation, physical activity, weight loss, and diet. In this paper we use population impact measures to estimate the potential impact of the implementation of these aspects of the NSF for CHD in England.

\section{METHODS}

We obtained estimates of prevalence of AMI and heart failure from statistics provided in the British Heart Foundation web site. ${ }^{5}$ The relative risk reductions associated with both pharmacological and lifestyle interventions were obtained from recent meta-analyses or systematic reviews where available. An estimate of baseline risk of mortality was derived from two studies that described the outcome of patients admitted to hospital with a diagnosis of heart failure or a first admission for AMI in Scotland. ${ }^{67}$ We used the published mortality rates to estimate age and sex stratified risk of death after hospital discharge. We estimated the proportion of AMI and HF patients eligible for and currently receiving these interventions from UK based studies of primary care treatment patterns. Data on proportions of patients adhering to treatment were obtained from international studies in the absence of available published data relating to UK patients.

In this analysis we used two population impact measures; the "number of events prevented in your population" (NEPP) and the "number to be treated in your population" (NTP). Both of these measures have been described elsewhere ${ }^{3}$ for treatment with a single intervention and have been expressed algebraically as:

$$
N E P P=n \times P_{d} \times r_{u} \times P_{e} \times R R R
$$

and

$$
N T P=n \times P_{d} \times P_{e}
$$

where $n$ is population size, $P_{d}$ is the prevalence of disease, $r_{u}$ is the risk in the untreated, $P_{e}$ is the proportion eligible for treatment, and $R R R$ is the relative risk reduction associated with the treatment.

Abbreviations: AMI, acute myocardial infarction; NSF, National Service Framework; CHD, coronary heart disease; NEPP, number of events prevented in population; NTP, number to be treated in population; PSSRU, Personal Social Services Research Unit 
The NEPP is used in this paper to estimate the extra number of events prevented in one year by the change from current practice to best practice if the NSF recommendations were implemented for drug treatment and lifestyle modification. The NTP is the number of people to be treated with each intervention package.

In our analyses we are assuming that patients receive a combination of treatments thus formula 1 has been modified. Mant and Hicks ${ }^{8}$ provide a comparatively simple formula for combining the proportion of patients treated with each drug and the different relative risk reductions associated with these drugs to get an overall treatment benefit associated with the drug combination. Mant and Hicks ${ }^{8}$ suggest that cumulative relative benefit of $n$ treatments can be estimated as

$$
\begin{aligned}
& 1-\left[\left(1-P_{t 1} \times R R R_{1}\right) \times\left(1-P_{t 2} \times R R R_{2}\right)\right. \\
& \left.\times \ldots \times\left(1-P_{t n} R R R_{n}\right)\right]
\end{aligned}
$$

where $R R R_{1}$ is the relative risk reduction associated with treatment 1 and $P_{t 1}$ is the proportion of the population treated with treatment $1, R R R_{2}$ is the relative risk reduction associated with treatment 2 , and $P_{t 2}$ is the proportion of the population treated with treatment 2 , etc.

To reflect the incremental effect of changing from current $P_{t}$, to "best" $P_{b}$, practice and adjusting for levels of treatment adherence $P_{a}$, the original version of NEPP, that simply estimated the number of events prevented if all eligible were treated, has been refined. To calculate the NEPP for an incremental increase in combination therapy we use $P_{\text {einc }}$ to represent the incremental change in the proportion eligible for treatment so we have:

$$
\begin{aligned}
& N E P P=n \times P_{d} \times r_{u} \times\left[1-\left(1-P_{\text {einc1 }} \times R R R_{1}\right)\right. \\
& \left.\times\left(1-P_{\text {einc } 2} \times R R R_{2}\right) \times \ldots \times\left(1-P_{\text {eincn }} \times R R R_{n}\right)\right]
\end{aligned}
$$

where

$$
\begin{aligned}
P_{\text {einc1 }} & \times R R R_{1}=P_{b 1} \times P_{a 1} \\
& \times R R R_{1}-P_{t 1} \times P_{a 1} \times R R R_{1}, \\
P_{\text {einc } 2} \times & R R R_{2}=P_{b 2} \times P_{a 2} \times R R R_{2}-P_{t 2} \\
\times & P_{a 2} \times R R R_{2}, \\
P_{\text {eincn }} \times & R R R_{n}=P_{b n} \times P_{a n} \times R R R_{n}-P_{t n} \\
\times & P_{a n} \times R R R_{n}
\end{aligned}
$$

for each of $\mathrm{n}$ treatments.
The risk in untreated patients, $r_{u}$ is derived from the overall risk, the proportion treated with each intervention and the relative risk reduction associated with each intervention (see appendix available on line http://www.jech.com/supplemental). ${ }^{9}$ Our analysis assumed a one year time horizon, therefore we used one year period prevalence of AMI and prevalence of heart failure to estimate the number of events prevented in new cases if NSF targets were met. Formula 3 assumes that the separate RRRs are independent for each drug as are the proportion receiving each drug (that is, the patients chance of receiving a particular drug does not depend on their receipt of other drugs). It is reasonable to assume that the effects of the CHD drugs that we are modelling are independent and there is little evidence to invalidate the independence assumption between the classes of drugs described in this paper. ${ }^{10}$ Data from the Quality and Incentives in Practice ${ }^{11}$ (QUIP) database provided by the National Primary Care Research and Development Centre (NPCRDC) suggest that the proportions of post-AMI patients treated with combinations of aspirin, $\beta$ blockers, statins, and ACE-I are independent. The QUIP data also show that this assumption holds for lifestyle data but to a lesser degree. More patients get no interventions and more patients get two or more interventions than we would expect under the assumption of independence.

The incremental costs for implementing each intervention according to NSF recommendations compared with current practice were calculated using the best published estimates available. The total costs were calculated by multiplying resource use by the unit cost for each item. All costs were based on unit costs for the price year 2002 and the perspective was that of the NHS. The unit costs for each drug prescribed were obtained from the British National Formulary ${ }^{12}$ and were applied to the most commonly used drug in each class based on data from the Prescriptions Cost Analysis (PCA) data for 2002. The cost of prescribing was obtained from Marshall ${ }^{13}$ and an additional cost of gastrointestinal bleeds in $2.5 \%$ of aspirin patients was included. ${ }^{14}$ The Personal Social Services Research Unit ${ }^{15}$ (PSSRU) estimates the cost of a GP consultation to be $£ 20^{15}$ and if we assume four visits per year this gives a cost of $£ 80$ per patient. For the lifestyle based analysis PSSRU provides cost per contact for a health visitor as $£ 29$ in 2002, assuming three visits per year ${ }^{16}$ then the annual cost of providing lifestyle based advice is $£ 87$ per patient.

\begin{tabular}{|c|c|c|c|c|c|}
\hline & & \multirow[b]{2}{*}{ Sex } & \multicolumn{3}{|c|}{ Age group } \\
\hline & & & $55-64$ & $65-74$ & $75+$ \\
\hline \multirow[t]{2}{*}{ Post-AMI patients } & One year period prevalence $(\%)^{18}$ & $\begin{array}{l}M \\
F\end{array}$ & $\begin{array}{l}0.8 \\
0.7\end{array}$ & $\begin{array}{l}1.8 \\
1.0\end{array}$ & $\begin{array}{l}1.2 \\
0.8\end{array}$ \\
\hline & Risk of death by one year ${ }^{7}(\%)$ & $M$ & $\begin{array}{l}4.65 \\
620\end{array}$ & 8.25 & $\begin{array}{l}13.50 \\
17.99\end{array}$ \\
\hline \multirow[t]{3}{*}{ Heart failure } & Prevalence $(\%)^{19}$ & $M$ & 2.73 & 4.17 & 8.77 \\
\hline & Risk of death by one year ${ }^{20}(\%)$ & $M$ & 19.02 & $\begin{array}{r}1.64 \\
23.34\end{array}$ & $\begin{array}{r}7.35 \\
27.78\end{array}$ \\
\hline & & $\mathrm{F}$ & 19.07 & 23.41 & 27.86 \\
\hline
\end{tabular}

We used a simulation technique ${ }^{17}$ to provide confidence intervals for our estimates of NEPP and NTP. This technique entails simulation from theoretical distributions based on the data used to calculate NEPP and NTP. A simulation based distribution of each statistic is produced and the 95\% confidence interval is obtained from the 2.5th and 97.5th centiles of the simulated distribution. 
Table 2 Relative risk reduction for death from any cause in post-AMI patients

\begin{tabular}{llll}
\hline & \multicolumn{2}{l}{ Relative risk reduction } & \\
\cline { 2 - 3 } & RRR & $95 \% \mathrm{Cl}$ & Source \\
\hline Antiplatelet & 0.12 & $(0.02,0.22)$ & Baigent $^{21}$ \\
$\beta$ blockers & 0.23 & $(0.15,0.31)$ & Freemantle $^{22}$ \\
Statins & 0.21 & $(0.10,0.30)$ & Ward $^{23}$ \\
ACE-I & 0.17 & $(0.03,0.29)$ & Domanski $^{24}$ \\
Smoking cessation & 0.36 & $(0.29,0.42)$ & Critchley $^{25}$ \\
Dietary intervention & 0.20 & $(-0.20,0.50)$ & Bucher $^{26}$ \\
Increased exercise & 0.27 & $(0.02,0.46)$ & Jolliffe $^{27}$ \\
\hline
\end{tabular}

\section{RESULTS}

The literature review provided estimates of the one year period prevalence of AMI and prevalence of heart failure in the general population as well as the risk of death one year after diagnosis split by age and sex. Table 1 shows these data.

Tables 2 and 3 show the relative risk reductions associated with each intervention for post-AMI patients and heart failure patients respectively.

Using data from the QUIP database we estimated that $84 \%$ of post-AMI patients are prescribed aspirin, $61 \%$ are prescribed $\beta$ blockers, $49 \%$ are prescribed ACE inhibitors, and $72 \%$ are prescribed statins. Using data from several UK based studies we estimated that $94 \%$ of post-AMI patients are eligible for treatment with aspirin, ${ }^{33-36} 80 \%$ are eligible for treatment with $\beta$ blockers, ${ }^{34-37} 80 \%$ are eligible for treatment with statins, ${ }^{2}$ and $75 \%$ are eligible for treatment with ACE-I. ${ }^{2}$ Data obtained mainly from studies conducted in North America, because of a lack of such information being reported in UK studies, showed that $84 \%$ of patients adhere to treatment with aspirin, ${ }^{38-41} 81 \%$ adhere to treatment with $\beta$ blockers, ${ }^{39-41} 81 \%$ adhere to treatment with statins, ${ }^{39-43}$ and $82 \%$ adhere to treatment with ACE inhibitors. ${ }^{39-41}$

For heart failure the General Practice Research Database ${ }^{44}$ provided the percentage of heart failure patients who were treated with $\beta$ blockers and ACE inhibitors by age and sex between 1994 and 1998. This varied from 7.5\% of women aged over 75 years prescribed $\beta$ blockers to $72 \%$ of men aged 55-64 years prescribed ACE inhibitors. We increased each of the age and sex specific percentages by an average of 10 percentage points to reflect current practice. For spironolactone, the percentages were not available split by age and sex and our the estimated treatment rate was $25 \% .{ }^{9}$ Studies have suggested that $65 \%$ of heart failure patients are eligible for treatment with $\beta$ blockers, ${ }^{45} 80 \%$ are eligible for treatment with ACE inhibitors, and $84 \%{ }^{45}$ are eligible for treatment with spironolactone. ${ }^{9}$ It proved difficult to obtain information on drug specific levels of adherence for patients with heart failure. There was no such information available for patients in the UK and the data used are from Germany ${ }^{46}$ and the USA $^{47}$ that estimate that $77 \%$ of patients adhere to spironolactone and $\beta$ blockers and $71 \%$ adhere with treatment with ACE inhibitors.
Estimates of the percentage of the post-AMI/CHD population who were eligible for, received, and adhered to lifestyle based interventions were derived from population based studies in the UK. These studies suggest that $29 \%$ of this population smoke, ${ }^{48-55} 52 \%$ have poor diet, ${ }^{49} 68 \%$ are overweight, ${ }^{49-5153} 20 \%$ are obese, ${ }^{49-51} 5455$ and $38 \%$ do little or no exercise. ${ }^{49}{ }^{51}$ Several studies also provided information on the percentage of those who were eligible for an intervention that received the intervention in normal general practice. Of those who were eligible for smoking cessation advice, $56 \%^{50} 52$ received such advice and similarly, of those who were eligible, $14 \%{ }^{52}$ received dietary advice, and $26 \%{ }^{50}$ received advice on increasing levels of exercise. In some cases it was also possible to establish from the study the proportion that complied with the advice. In the case of advice on giving up smoking around $32 \%$ of patients gave up for at least six months after GP/nurse advice. ${ }^{485} 56$ About $34 \%$ of those who received advice improved their $\operatorname{diet}^{16}$ and $34 \%$ had increased levels of exercise after two years. ${ }^{16}$ Information on lifestyle based interventions was even more limited for heart failure patients and therefore proportions used for CHD were applied to the heart failure analysis. There was no evidence that obesity $^{5758}$ conveyed an increased risk of death in heart failure patients so the lifestyle based analysis for this group focused on smoking cessation and increasing exercise alone.

Table 4 shows the number of deaths that would be prevented per year in England by adopting the NSF recommendations for change from current to best practice for pharmacological and lifestyle based secondary intervention for post-AMI and heart failure patients. (A worked example is provided in the appendix, which is available on line http://www.jech.com/supplemental)

The population impact of the two types of intervention split by age and sex are shown in figure 1 for post-AMI patients and figure 2 for heart failure patients.

\section{DISCUSSION}

The number of deaths prevented by the introduction of health care interventions depends on baseline risk, disease prevalence, treatment levels, and the relative risk reduction achieved by the intervention. In our example the number of deaths prevented over one year through implementation of

Table 3 Relative risk reduction for death from any cause in heart failure patients

\begin{tabular}{llll}
\hline & \multicolumn{2}{l}{ Relative risk reduction } & \\
\cline { 2 - 3 } & RRR & $95 \% \mathrm{Cl}$ & Source \\
\hline$\beta$ blockers & 0.35 & $(0.26,0.43)$ & Shibata $^{28}$ \\
ACE-I & 0.26 & $(0.17,0.34)$ & Flather $^{29}$ \\
Spironolactone & 0.30 & $(0.18,0.40)$ & Pitt $^{30}$ \\
Smoking cessation & 0.29 & $(0.20,0.37)$ & Suskin $^{31}$ \\
Increasing exercise & 0.56 & $(0.13,0.78)$ & Rees $^{32}$ \\
\hline
\end{tabular}


Table 4 Impact of change from current to best practice in pharmacological and lifestyle based interventions among post-AMl and heart failure patients in England

\begin{tabular}{llllll}
\hline & \multicolumn{2}{l}{ Post-AMI patients } & \multicolumn{2}{l}{ Heart failure patients } \\
\cline { 2 - 3 } & Drug & Lifestyle & & Drug & Lifestyle \\
\hline Number of deaths prevented & 1027 & 848 & & 37899 & 7249 \\
Number of people treated & 37286 & 76317 & & 353443 & 149044 \\
Total cost of treatment* & $£ 6641600$ & $£ 6639569$ & & 53702193 & $£ 12966868$ \\
Cost per death prevented* & $£ 6464$ & $£ 7834$ & & $£ 1417$ & $£ 1789$ \\
\hline *Price year 2002. & & & & \\
\hline
\end{tabular}

the targets recommended in the NSF for CHD is greatest for heart failure patients aged over 75 years. Meeting pharmacological based recommendations among these patients will prevent significantly more deaths than meeting lifestyle based interventions. Furthermore, our analysis suggests that achieving the NSF targets for heart failure will have a much greater impact on one year mortality rates than achieving the NSF targets for post-AMI patients. This is probably because of the poor one year survival rate among heart failure patients and because heart failure patients are currently less likely to be near "best" practice levels.

The NEPP provides a useful measure of the population impact of an intervention and until now has only been used to compare single drug interventions. Using the NEPP to assess the population impact of a combination of treatments however requires the assumption of independence of relative risk reduction and the proportion eligible for treatment and this might not always be the case. However, it is the inclusion of these parameters in the statistic that make it relevant to policy makers. If only a small proportion of the population are eligible for an intervention then even if it is highly effective, more impact may be had by introducing a less effective intervention that reaches more of the population. Population impact numbers can help a policy maker make these judgements.

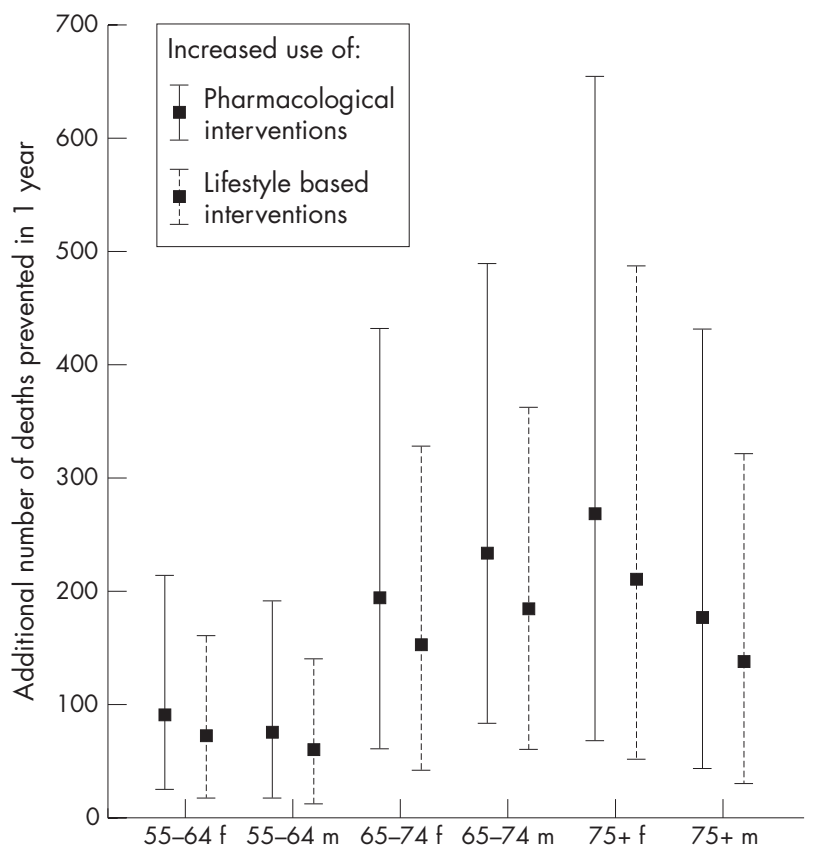

Figure 1 Number of deaths prevented in post-AMl patients if current practice was modified to meet the recommendations specified in the NSF.
This analysis has used published data to estimate the potential impact of the NSF for CHD in England over one year. There are several limitations associated with using published data. For example, it was difficult to find information for each component of the NEPP divided into the same age and sex categories. It is probable that the proportion treated and adhering to treatment varies by age and sex. It is also possible that relative risk reductions identified in patient groups selected for clinical trials may not be reflected in the general population. In particular, the relative risk reduction for exercise based intervention for heart failure patients although derived from a meta-analysis was actually only based on one trial ${ }^{59}$ that recorded mortality. Furthermore, many published sources use imprecise definitions of disease status and outcome. In our particular example the NSF itself is rather vague, making the process of identifying the most appropriate source of data even more difficult. The paucity of published data in this field has been described by other researchers. Unal, ${ }^{60}$ in a study evaluating the effect of population level changes in risk factors and the development of treatments on levels of CHD in England and Wales, commented that "Limited primary care data on consultation rates, prescribing and treatment uptake were available from published audits and studies." Rutten ${ }^{61}$ also commented that "Data on diagnosis and management of

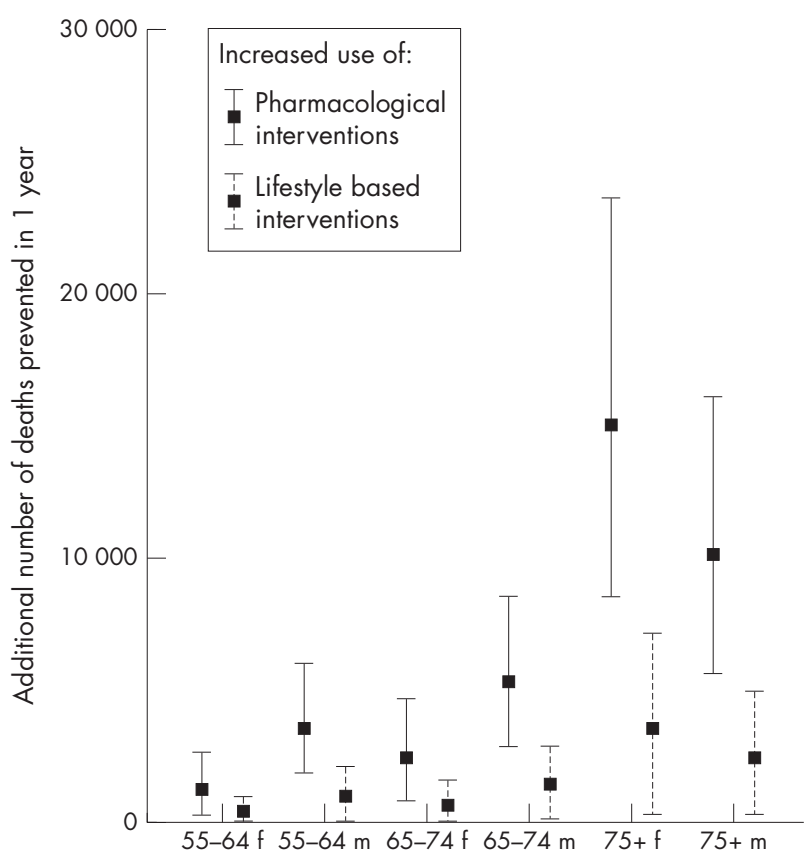

Figure 2 Number of deaths prevented in heart failure patients if current practice was modified to meet the recommendations specified in the NSF. 


\section{Policy implications}

- Changing from current to best practice for pharmacological treatments for heart failure patients would prevent more deaths in the first year after diagnosis than similar changes in treatment for post-AMI patients.

- Population impact measures can be used to provide a population focus to the impact of evidence based practice and could be used at the local (primary care trust) level to evaluate the local impact of implementing a range of health care targets.

heart failure in every-day care are scarce" while Capewell ${ }^{7}$ commenting on the lack of availability of information on risk of death after AMI stated that "Population based studies are uncommon, the recent outstanding example being MONICA. This, however concentrated on 28 day survival." In this analysis we have used a one year end point because this was the most consistent of the time periods for which we could obtain outcomes in the various studies reviewed. A longer time frame may change the relative importance of different interventions both within and between conditions as levels of treatment, adherence to treatment, and costs will vary over time.

The limitations in the underlying measures may undermine the public health message presented here, however this analysis shows the strength of this type of methodology in assessing the impact of a population based intervention such as the NSF for CHD. There is thus a cogent need both to improve the routine collection, quality, and accessibility of local and national morbidity, prescribing, and adherence data both for pharmacological, lifestyle, and other interventions if the full potential of evidence based medicine based on sources, such as randomised clinical trials, is to be realised and used to its utmost effect in planning healthcare on a population level.

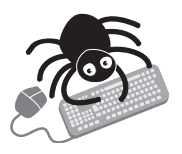

The appendix giving a worked example of the method used in this article is available on line (http:// www.jech.com/supplemental).

\section{Authors' affiliations}

I Gemmell, R F Heller, P McElduff, G Butler, R Edwards, Evidence for Public Health Unit, School of Epidemiology and Health Sciences, University of Manchester, Manchester, UK

K Payne, North West Genetics Knowledge Park, University of Manchester

M Roland, National Primary Care Research and Development Centre, University of Manchester

P Durrington, Division of Cardiovascular and Endocrine Science, Department of Medicine, Manchester Royal Infirmary

Funding: this work has been funded by a British Heart Foundation grant (PG/03/047/15339).

Competing interests: none declared.

\section{REFERENCES}

1 Heller RF, Dobson AJ. Disease impact number and population impact number: population perspectives to measures of risk and benefit. $B M J$ 2000;321:950-2.

2 Heller RF, Edwards R, McElduff P. Implementing guidelines in primary care: can population impact measures help? BMC Public Health 2003;3:7.

3 Heller RF, Page J. A population perspective to evidence based medicine: "evidence for population health". I Epidemiol Community Health 2002;56:45-7.
4 Department of Health. National service framework for coronary heart disease: modern standards and service models. London: Sationery Office, 2000.

5 Heartstats. http://www. heartstats.org/homepage.asp (accessed Nov 2004).

6 Cowie MR, Wood DA, Coats AJS, et al. Incidence and aetiology of heart failure-a population-based study. Eur Heart J 1999;20:421-8.

7 Capewell S, Livingston BM, Maclntyre K, et al. Trends in case-fatality in 117 718 patients admitted with acute myocardial infarction in Scotland. Eur Heart $J$ 2000;21:1833-40.

8 Mant J, Hicks N. Detecting differences in quality of care-the sensitivity of measures of process and outcome in treating acute myocardial infarction. $B M J$ 1995;311:793-6.

9 Lyratzopoulos G, Cook GA, McElduff P, et al. Assessing the impact of heart failure specialist services on patient populations. BMC Health Services Research 2004;24:10.

10 Latini R, Tognoni G, Maggioni AP, et al. Clinical effects of early angiotensinconverting enzyme inhibitor treatment for acute myocardial infarction are similar in the presence and absence of aspirin-systematic overview of individual data from 96,712 randomized patients. J Am Coll Cardiol 2000;35:1801-7.

11 National Primary Care Research and Development Centre. http:// www.npcrdc.man.ac.uk/ResearchDetail.cfm?|D = 1 18\&txtSearch = quip (accessed Jan 2005).

12 Royal Pharmaceutical Society of Great Britain. British National Formulary. London: British Medical Association, 2002.

13 Marshall T, Rouse A. Resource implications and health benefits of primary prevention strategies for cardiovascular disease in people aged 30 to 74 mathematical modelling study. BMJ 2002;325:197-9.

14 Almela P, Benages A, Peiro S, et al. Outpatient management of upper digestive hemorrhage not associated with portal hypertension: a large prospective cohort. Am J Gastroenterol 2001;96:2341-8.

15 Netten A, Curtis L. Unit costs of health and social care 2003. Canterbury: University of Kent at Canterbury, Personal Social Services Research Unit, 2003.

16 Cupples ME, McKnight A. Randomized controlled trial of health promotion in general practice for patients at high cardiovascular risk. BMJ 1994;309:993-6

17 Greenland $\mathrm{S}$. Interval estimation by simulation as an alternative to and extension of confidence intervals. Int J Epidemiol 2004:33:1389-97.

18 Primatesta P. Prevalence of cardiovascular disease. In: Health survey for England 1998. London: The Stationery Office, 1999.

19 Davies MK, Hobbs FDR, Davis RC, et al. Prevalence of left-ventricular systolic dysfunction and heart failure in the echocardiographic heart of England screening study: a population based study. Lancet 2001;358:439-44.

20 Macintyre K, Capewell S, Stewart S, et al. Evidence of improving prognosis in heart failure-trends in case fatality in 66547 patients hospitalized between 1986 and 1995. Circulation 2000;102:1126-31.

21 Baigent C, Sudlow C, Collins R, et al. Collaborative meta-analysis of randomised trials of antiplatelet therapy for prevention of death, myocardial infarction, and stroke in high risk patients. BMJ 2002;324:71-86.

22 Freemantle N, Cleland J, Young P, et al. Beta blockade after myocardial infarction: systematic review and meta regression analysis. BMJ 1999:318:1730-7.

23 Ward S, Lloyd Jones M, Pandor A, et al. Statins for the prevention of coronary events. London: NICE, 2005

24 Domanski MJ, Exner DV, Borkowf CB, et al. Effect of angiotensin converting enzyme inhibition on sudden cardiac death in patients following acute myocardial infarction-a meta-analysis of randomized clinical trials. J Am Coll Cardiol 1999;33:598-604.

25 Critchley JA, Capewell S. Mortality risk reduction associated with smoking cessation in patients with coronary heart disease - a systematic review. JAMA 2003;290:86-97.

26 Bucher $\mathrm{HC}$, Hengstler $\mathrm{P}$, Schindler $\mathrm{C}$, et al. N-3 polyunsaturated fatty acids in coronary heart disease: a meta-analysis of randomized controlled trials. Am J Med 2002;112:298-304.

27 Jolliffe J, Rees K, Taylor R, et al. Exercise-based rehabilitation for coronary heart disease. Cochrane Library. Chichester: Wiley, 2004.

28 Shibata MC, Flather MD, Wang DL. Systematic review of the impact of beta blockers on mortality and hospital admissions in heart failure. European Journal of Heart Failure 2001;3:351-7.

29 Flather MD, Yusuf S, Kober L, et al. Long-term ACE-inhibitor therapy in patients with heart failure or left-ventricular dysfunction: a systematic overview of data from individual patients. Lancet 2000;355:1575-81

30 Pitt B, Zannad F, Remme WJ, et al. The effect of spironolactone on morbidity and mortality in patients with severe heart failure. N Engl J Med 1999;341:709-17.

31 Suskin N, Sheth T, Negassa A, et al. Relationship of current and past smoking to mortality and morbidity in patients with left ventricular dysfunction. J Am Coll Cardiol 2001;37:1677-82.

32 Rees K, Taylor R, Singh S, et al. Exercise based rehabilitation for heart failure. Cochrane Library. Chichester: Wiley, 2004.

33 Hedman J, Kaprio J, Poussa T, et al. Prevalence of asthma, aspirin intolerance, nasal polyposis and chronic obstructive pulmonary disease in a population-based study. Int J Epidemiol 1999;28:717-22.

34 Dudley NJ, Bowling A, Bond M, et al. Age- and sex-related bias in the management of heart disease in a district general hospital. Age Ageing 2002:31:37-42.

35 Brotons C, Permanyer G, Pacheco V, et al. Prophylactic treatment after myocardial infarction in primary care: how far can we go? Fam Pract 2003;20:32-5. 
36 Brotons $\mathrm{C}$, Calvo $\mathrm{F}$, Cascant $\mathrm{P}$, et al. Is prophylactic treatment after myocardial infarction evidence- based? Fam Pract 1999;16:94

37 Sarasin FP, Maschiangelo ML, Schaller MD, et al. Successful implementation of guidelines for encouraging the use of beta blockers in patients after acute myocardial infarction. Am J Med 1999;106:499-505.

38 Newby LK, Bhapkar MV, White HD, et al. Aspirin use post-acute coronary syndromes: intolerance, bleeding and discontinuation. Journal of Thrombosis and Thrombolysis 2003;16:119-28.

39 Simpson E, Beck C, Richard H, et al. Drug prescriptions after acute myocardial infarction: dosage, compliance, and persistence. Am Heart J 2003; 145:438-44.

40 Cotter G, Shemesh E, Zehavi M, et al. Lack of aspirin effect: Aspirin resistance or resistance to taking aspirin? Am Heart J 2004; 147:293-300.

41 Eagle KA, Kline-Rogers E, Goodman SG, et al. Adherence to evidence-based therapies after discharge for acute coronary syndromes: an ongoing prospective, observational study. Am J Med 2004;117:73-81.

42 Larosa JH, Larosa JC. Enhancing drug compliance in lipid-lowering treatment. Arch Fam Med 2000;9:1 169-75.

43 Insull W. The problem of compliance to cholesterol altering therapy. J Intern Med 1997;241:317-25.

44 Ellis C, Shamini G, Majeed A. Prevalence and management of heart failure in general practice in England and Wales, 1994-1998. Health Statistics Quarterly 2001;11:17.

45 Cowie MR, Mclntyre H, Panahloo Z. Delivering evidence-based care to patients with heart failure: results of a strucured programme. Cardiology in General Practice 2004;9:171-80

46 Michalsen A, Konig G, Thimme W. Preventable causative factors leading to hospital admission with decompensated heart failure. Heart 1998:80:437-41.

47 Roe CM, Motheral BR, Teitelbaum F, et al. Angiotensin-converting enzyme inhibitor compliance and dosing among patients with heart failure. Am Heart $J$ 1999;138:818-25.

48 Jolly K, Bradley F, Sharp S, et al. Randomised controlled trial of follow up care in general practice of patients with myocardial infarction and angina: final results of the Southampton heart integrated care project (SHIP). BMJ 1999;318:706-11.

49 Campbell NC, Thain J, Deans HG, et al. Secondary prevention in coronary heart disease: baseline survey of provision in general practice. BMJ 1998;316:1430-4.
50 Kotseva K, Wood D, De Backer G, et al. Lifestyle and risk factor management and use of drug therapies in coronary patients from 15 countries-principal results from EUROASPIRE II Euro heart survey programme. Eur Heart $J$ 2001;22:554-72.

51 Flanagan DEH, Cox P, Paine D, et al. Secondary prevention of coronary heart disease in primary care: a healthy heart initiative. Monthly Journal of the Association of Physicians 1999;92:245-50.

52 Feder G, Griffiths C, Eldridge S, et al. Effect of postal prompts to patients and general practitioners on the quality of primary care after a coronary event (POST): randomised controlled trial. BMJ 1999;318:1522-6.

53 Fox KF, Wood DA, Wright $M$, et al. Evaluation of a cardiac prevention and rehabilitation programme for all patients at first presentation with coronary artery disease. J Cardiovasc Risk 2002;9:355-9.

54 Hippisley-Cox J, Pringle $M$, Crown N, et al. Sex inequalities in ischaemic heart disease in general practice: cross sectional survey. BMJ 2001;322:832-4A.

55 Carroll K, Majeed A, Firth C, et al. Prevalence and management of coronary heart disease in primary care: population-based cross-sectional study using a disease register. J Public Health Med 2003;25:29-35.

56 Corrigan M, Cupples ME, Stevenson M. Quitting and restarting smoking: cohort study of patients with angina in primary care. BMJ 2002;324:1016-17.

57 Horwich TB, Fonarow GC, Hamilton MA, et al. The relationship between obesity and mortality in patients with heart failure. J Am Coll Cardiol 2001;38:789-95.

58 Gustafsson F, Kragelund C, Torp-Pedersen C, et al. Effect of obesity and being overweight on long-term mortality in congestive heart failure: influence of left ventricular systolic function. Eur Heart J 2005;26:58-64.

59 Belardinelli R, Georgiou D, Cianci G, et al. Randomized, controlled trial of long-term moderate exercise training in chronic heart failure-effects on functional capacity, quality of life, and clinical outcome. Circulation 1999;99:1173-82.

60 Unal B, Critchley JA, Capewell S. Missing, mediocre, or merely obsolete? An evaluation of UK data sources for coronary heart disease. J Epidemiol Community Health 2003;57:530-5.

61 Rutten FH, Grobbee DE, Hoes AW. Differences betweengeneral practitioners and cardiologists in diagnosis and management of heart failure: a survey in every-day practice. European Journal of Heart Failure 2003;5:337-44. 